\title{
Clinicopathological and prognostic impact of somatic mutations in Chinese patients with clear cell renal cell carcinoma
}

\author{
Hai Bi ${ }^{1 \#}$, Jipeng Yin ${ }^{1 \#}$, Lang Zhou ${ }^{1}$, Yaqian $W^{1}{ }^{1}$, Liyuan $\mathrm{Ge}^{1}$, Min $\mathrm{Lu}^{2}$, Lei Liu ${ }^{1}$, Hongxian Zhang ${ }^{1}$, \\ Yongzhe Zhao ${ }^{3}$, Cheng Liu ${ }^{1}$, Lulin $\mathrm{Ma}^{1}$ \\ ${ }^{1}$ Department of Urology, Peking University Third Hospital, Beijing, China; ${ }^{2}$ Department of Pathology, Peking University Third Hospital, Beijing, \\ China; ${ }^{3}$ Department of Urology, Peking University Third Hospital Yanqing Hospital, Beijing, China \\ Contributions: (I) Conception and design: C Liu, L Ma; (II) Administrative support: C Liu, L Ma; (III) Provision of study materials or patients: H \\ Bi, L Zhou, H Zhang; (IV) Collection and assembly of data: H Bi, L Zhou, H Zhang; (V) Data analysis and interpretation: H Bi, Y Wu, C Liu; (VI) \\ Manuscript writing: All authors; (VII) Final approval of manuscript: All authors. \\ \#These authors contributed equally to this work. \\ Correspondence to: Lulin Ma, MD, PhD; Cheng Liu, MD, PhD. Department of Urology, Peking University Third Hospital, 49 North Garden Rd, \\ Haidian District, Beijing 100191, China. Email: malulin@medmail.com.cn; chengliu@bjmu.edu.cn; Yongzhe Zhao, MD, PhD. Department of \\ Urology, Peking University Third Hospital Yanqing Hospital, 28 East Shuncheng Rd., Yanqing District, Beijing 102100, China. \\ Email: 781090128@qq.com.
}

Background: The study of the genomic landscape of Chinese clear cell renal cell carcinoma (ccRCC) entered its nascence in recent years, and the clinical relevance of individual genes in Chinese ccRCC has not yet been researched. The study aimed to explore the relationships between somatic mutations and clinical behaviors in Chinese ccRCC.

Methods: Tumor tissue samples were obtained from 105 Chinese patients with ccRCC and deep sequencing targeting 556 cancer genes was performed. Correlation analysis, receiver operator characteristic (ROC) analysis and survival analysis were carried out using SPSS software.

Results: A total of 41 genes were used to investigate the relationship between genes and clinical behaviors. We found that different clinical indices were mutually correlated, and there were 12 genes associated with clinical indices. The Kaplan-Meier curves showed that high Fuhrman grade and metastatic disease at diagnosis were significantly associated with poor prognosis. Mutations in BAP1, PTEN, ERBB2, TP53, $C D K 8, T S C 1, S E T D 2$, or SPEN were significantly associated with poor prognosis, consistent with the results of The Cancer Genome Atlas (TCGA) cohort. Mutation of BTG1 occurred much more frequently in Chinese ccRCC (10.5\%) than in the TCGA cohort (0.60\%), and it was associated with a better prognosis.

Conclusions: A total of 8 genes (BAP1, PTEN, ERBB2, TP53, CDK8, TSC1, SETD2, and SPEN) were found to be associated with poor prognosis of ccRCC, and a new gene (BTG1) was possibly associated with the good prognosis of Chinese ccRCC.

Keywords: Clear cell renal cell carcinoma (ccRCC), targeted next-generation sequencing (targeted NGS), correlation analysis, survival analysis, prognostic biomarker

Submitted Oct 19, 2020. Accepted for publication Dec 09, 2020.

doi: $10.21037 /$ tau-20-1410

View this article at: http://dx.doi.org/10.21037/tau-20-1410 


\section{Introduction}

Renal cell carcinoma (RCC) is one of the most common malignant neoplasm arising from the kidney, representing about $2 \%$ of all human malignancies, with 403,262 new cases and 175,098 related deaths estimated worldwide in 2018 (1). Clear-cell (cc) RCC is the most common subtype, accounting for up about $80 \%$ of all RCC cases (2). TNM stage and Fuhrman grade are the most commonly used predictors of clinical outcome for patients with ccRCC. However, patients with similar clinical features may have diverse outcomes. A commonly used stratification tool, Memorial Sloan Kettering Cancer Center (MSKCC) risk model, allows stratification of patients with RCC into one of three categories (favourable, intermediate, or poor prognosis) (3). One of the main limitations of this model is that most patients were typically classified as intermediate risk. Thus, there is a need to add prognostic value to the current stratification tools, which has been initially achieved with the use of validated genetic biomarkers (4). In addition, the promising curative effect of targeted therapies drove the studies on genomic research on ccRCC, intending to discover the putative targets in RCC pathogenesis $(5,6)$. With the increasing treatment methods for RCC, selecting the right therapy for the right individual becomes crucial. Fortunately, the use of genomic research in clinical trials has begun to clarify the predictive or prognostic roles of certain genomic alterations in guiding RCC outcomes (7).

Genomic research has been conducted extensively in ccRCC, in which the mutation frequency of VHL, PBRM1, SETD2, BAP1, KDMSC, TP53, and MTOR is $52 \%, 30 \%$, $13 \%, 13 \%, 7 \%, 7 \%$, and $7 \%$, respectively. Many studies have focused on identifying the clinical relevance of individual genes (7-10). Growing evidence supports the prognostic value of chromatin remodeling genes, such as PBRM1, BAP1, SETD2, and EZH2, as well as the DNA damage repair (DDR) genes (7). Most of the studies were performed on patients from Western countries, and little is known about the genomic landscape of Chinese ccRCC and how it differs from that of Western cohorts. In recent years, the genomic landscape of Chinese ccRCC has been depicted by limited studies (11-13); however, the clinical relevance of individual genes in Chinese ccRCC has not been studied yet.

In this study, we performed deep sequencing targeting 556 cancer genes on 105 Chinese patients with ccRCC and investigated the clinicopathological significance of frequently mutated genes.
We present the following article in accordance with the REMARK reporting checklist (available at http://dx.doi. org/10.21037/tau-20-1410).

\section{Methods}

\section{Participants and samples}

Tumor tissue samples for genetic testing were taken from 105 participants with ccRCC who underwent surgery at the Peking University Third Hospital between August 2013 and March 2020, among which 103 patients were operated on after 2018. The treatments of these patients were randomized. We retrospectively collected the clinical and pathological data of these 105 participants. All procedures performed in this study involving human participants were in accordance with the Declaration of Helsinki (as revised in 2013). This study was approved by Peking University Third Hospital Medical Science Research Ethics Committee (No. M2018042). Written informed consent was provided by all participants.

We validated our findings using the dataset of ccRCC from The Cancer Genome Atlas (TCGA-KIRC) (August 8, 2019, update).

\section{Targeted next-generation sequencing (NGS)}

We extracted DNA from tissue samples, and the invasive tumor content was evaluated by pathologists, to ensure $>50 \%$ of cells were tumor cells. The DNA was isolated using the DNeasy Tissue Kit (69504, QIAGEN, Venlo, Netherlands). Multi-gene panel targeted NGS including 556 genes was performed on Ion Torrent (Tongshu BioTech, Shanghai, China). The targeted libraries were constructed using NGS Fast DNA Library Prep Set (Thermo Fisher, Waltham, MA, USA). Sequencing data were analyzed by TorrentSuit-5.6 (3730XL, Life Technologies Corp., Carlsbad, CA, USA) with mutation calling using VarDict (14). The clinicopathological significance of 41 genes with mutation frequencies $>3 \%$ was investigated.

\section{Statistical analysis}

Statistical analysis was performed using the software SPSS 25.0 (IBM Corp. Armonk, NY, USA). The correlations between different clinical indices, as well as the correlations between mutation status and clinical indices, were analyzed using crosstabs analysis. Fisher's exact test was 
Table 1 The clinicopathological features of 105 Chinese patients with ccRCC

\begin{tabular}{|c|c|}
\hline Items & Total $(n=105)$ \\
\hline \multicolumn{2}{|l|}{ Gender } \\
\hline Male & $82(78.1 \%)$ \\
\hline Female & $23(21.9 \%)$ \\
\hline \multicolumn{2}{|l|}{ Age } \\
\hline Median [range] & 58 [26-83] \\
\hline \multicolumn{2}{|l|}{ Clinical stage } \\
\hline I & $42(40.0 \%)$ \\
\hline II & $5(4.8 \%)$ \\
\hline III & $38(36.2 \%)$ \\
\hline IV & 20 (19.0\%) \\
\hline \multicolumn{2}{|l|}{$\mathrm{T}$} \\
\hline $\mathrm{T} 1$ & $43(40.9 \%)$ \\
\hline $\mathrm{T} 2$ & $5(4.8 \%)$ \\
\hline T3 & 55 (52.4\%) \\
\hline $\mathrm{T} 4$ & $2(1.9 \%)$ \\
\hline \multicolumn{2}{|l|}{$\mathrm{N}$} \\
\hline NO & 85 (81.0\%) \\
\hline $\mathrm{N} 1$ & $20(19.0 \%)$ \\
\hline \multicolumn{2}{|l|}{ M } \\
\hline MO & $85(81.0 \%)$ \\
\hline M1 & $20(19.0 \%)$ \\
\hline \multicolumn{2}{|l|}{ Fuhrman grade } \\
\hline 1 & $5(4.8 \%)$ \\
\hline 2 & $62(59.0 \%)$ \\
\hline 3 & $25(23.8 \%)$ \\
\hline 4 & $13(12.4 \%)$ \\
\hline \multicolumn{2}{|l|}{ Infringement } \\
\hline No & 47 (44.8\%) \\
\hline Yes & $58(55.2 \%)$ \\
\hline \multicolumn{2}{|l|}{ Necrosis } \\
\hline No & $79(75.2 \%)$ \\
\hline Yes & $26(24.8 \%)$ \\
\hline \multicolumn{2}{|l|}{ Sarcomatoid } \\
\hline No & 95 (90.5\%) \\
\hline Yes & $10(9.5 \%)$ \\
\hline \multicolumn{2}{|l|}{ Tumor thrombus } \\
\hline No & $80(76.2 \%)$ \\
\hline Yes & $25(23.8 \%)$ \\
\hline
\end{tabular}

ccRCC, clear cell renal cell carcinoma; T, tumor; N, node; $M$, metastasis. used to determine the associations. A receiver operator characteristic (ROC) curve was used to evaluate the performance of mutation status to predict clinical outcomes. The Kaplan-Meier method was used to analyze diseasefree survival (DFS) stratified by clinical indices or mutation status. Statistical significance was defined as two-tailed $\mathrm{P}$ values $<0.05$.

\section{Results}

\section{Clinicopathologic characteristics of ccRCC}

The clinicopathologic characteristics of ccRCC are summarized in Table 1. This cohort consisted of 82 (78.1\%) males and $23(21.9 \%)$ females. The participants' ages at diagnosis were $26-83$ years, and the median age was 58 years. There were $42(40.0 \%), 5(4.8 \%), 38(36.2 \%)$, and $20(19.0 \%)$ participants in clinical stage I, II, III, and IV, respectively. Tumor sizes were $2-12.8 \mathrm{~cm}$ (median size, $6 \mathrm{~cm}$ ), and there were $43(40.9 \%), 5(4.8 \%), 55(52.4 \%)$, and $2(1.9 \%)$ participants in stage T1, T2, T3, and T4, respectively. Metastatic disease was present in 34 (32.4\%) participants at the time of diagnosis. There were 5 (4.8\%), $62(59.0 \%), 25$ (23.8\%), and 13 (12.4\%) participants with Fuhrman grade 1, 2, 3, and 4, respectively. Among the 105 patients, 58 (55.2\%) were infringement, 26 (24.8\%) were necrosis, 10 (9.5\%) were sarcomatoid, and 25 (23.8\%) had tumor thrombi.

\section{The interrelationship between different clinical indices of $c c R C C$}

We studied the interrelationship between clinical indices, including gender, age at diagnosis, clinical stage, pathological T (pT) stage, metastasis at diagnosis, Fuhrman grade, infringement, necrosis, sarcomatoid, and tumor thrombus. As a result, we found that all clinical indices were correlated. As shown in Figure 1, the infringement is strongly associated with clinical stage and pT stage. The infringement rarely occured in lower stages (clinical stage I/II or pT1/2), but did so almost always in higher stages (clinical stage III/IV or pT3/4) (Table S1). The infringement was also associated with Fuhrman grade, tumor thrombus, necrosis, sarcomatoid, and metastasis at diagnosis. Infringement occurred in most of the participants with tumor thrombus $(96.0 \%$, Table S2), necrosis $(80.8 \%$, Table S3), sarcomatoid (100\%, Table S4), and metastasis at diagnosis (88.2\%) (Table S5). 


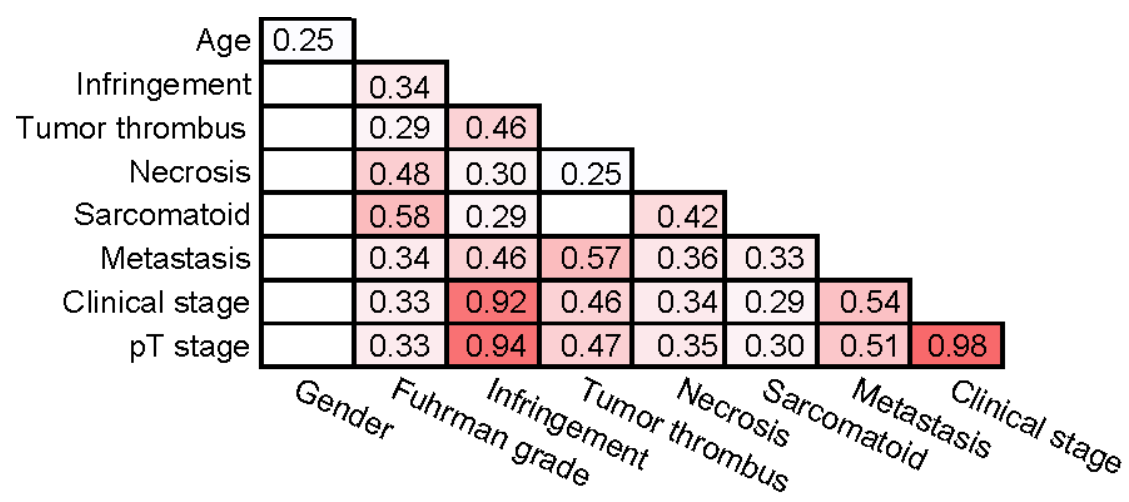

Figure 1 Correlation analysis between clinical indices $(\mathrm{P}<0.01)$. Red, positively correlated; blue, negatively correlated. Number, the correlation coefficients; blank, uncorrelated. pT, pathological T.

The result showed that the higher the Fuhrman grade, the higher the likelihood of infringement, tumor thrombus, necrosis, sarcomatoid, metastasis at diagnosis, and high stages (Table S6). Among the patients with Fuhrman grade 4 , the incidence of infringement, tumor thrombus, necrosis, sarcomatoid, metastasis, high clinical stage, and high pT stage was $92.3 \%, 53.8 \%, 76.9 \%, 53.8 \%, 69.2 \%, 92.3 \%$, and $92.3 \%$, respectively (Table S6).

Metastasis at diagnosis was associated with clinical stage, pT, Fuhrman grade, infringement, necrosis, sarcomatoid, and tumor thrombi (Figure 1). Patients with metastasis at diagnosis were often already in high stages (94.1\% in clinical stage III/IV and $91.2 \%$ in pT3/4, Table S3), and participants with high clinical stage or $\mathrm{pT}$ were predominantly metastatic at diagnosis $(95.2 \%$ and $93.0 \%$, respectively). Metastatic disease was found in most participants with tumor thrombus $(80.0 \%$, Table S2), necrosis $(61.5 \%$, Table $\mathrm{S} 3)$, and sarcomatoid $(80.0 \%$, Table S4).

The participants with tumor thrombus usually had necrosis $(44.0 \%)$ and high stages $(96.0 \%)$, but there was no relationship between tumor thrombus and sarcomatoid carcinoma (Table S2). Patients with sarcomatoid lesion or necrosis had a high probability of infringement, metastasis, and high stage (Table S3, Table S4). In addition, we found that male ccRCC patients were distributed through different age groups, while female ccRCC patients were mainly $>58$ years (Table S7).

\section{The relationship between genetic alterations and clinical indices of $c c R C C$}

Among the 556 cancer genes, 212 genes were detected in this cohort. The most frequently altered genes were $V H L$ (55.2\%), PBRM1 (34.3\%), ZFHX3 (16.2\%), ERBB2 (11.4\%), BTG1 (10.5\%), MET (10.5\%), BAP1 (9.5\%), FGFR3 (9.5\%), PIK3CB (8.6\%), SETD2 (8.6\%), and CCND1 (7.6\%). A total of 41 genes with alteration frequencies $>3 \%$ were used to investigate the relationship between genes and clinical behaviors (Figure 2). A total of 7 (TP53, BAP1, PIK3CB, CCND1, WWTR1, MTOR, and PTEN) were found to be significantly associated with at least one clinical index $(\mathrm{P}<0.05)$. Considering the relatively small size of our cohort, we expanded the $\mathrm{P}$-value to 0.1 , and an additional 5 genes (BTG1, BLM, ERBB2, PARP1 and MET) were included (Figure 3).

The results showed that mutations in $B A P 1, P I K 3 C B$, $W W T R 1$, and MTOR occurred more frequently in female (13.0-26.1\%) than male (1.2-6.1\%) ccRCC (Table S8). Mutations in TP53, BAP, 1 and PTEN were usually found in instances of higher Fuhrman grade (Table S9). Mutations in BAP1, ERBB2, and PARP1 were associated with the infringement (Table S10). Mutations of ERBB2, BAP1, and $P T E N$ were seen more frequently in RCC patients with metastasis at diagnosis, while $B T G 1$ and $B L M$ were mutated more frequently in RCC patients without metastasis at diagnosis (Table S11). Mutations of BAP1 and PARP1 were shown more frequently in higher pT stage (Table S12). More frequent mutation of BAP1 and MET was revealed in RCC patients with sarcomatoid carcinoma (Table S13). Moreover, $B A P 1$ was mutated more frequently in higher clinical stage, CCND1 was mutated more frequently in younger patients, PTEN was mutated more frequently in patients with tumor thrombus, and BTG1 was rarely mutated in patients with necrosis (Tables S14-S17).

The combinations of genes associated with a single 


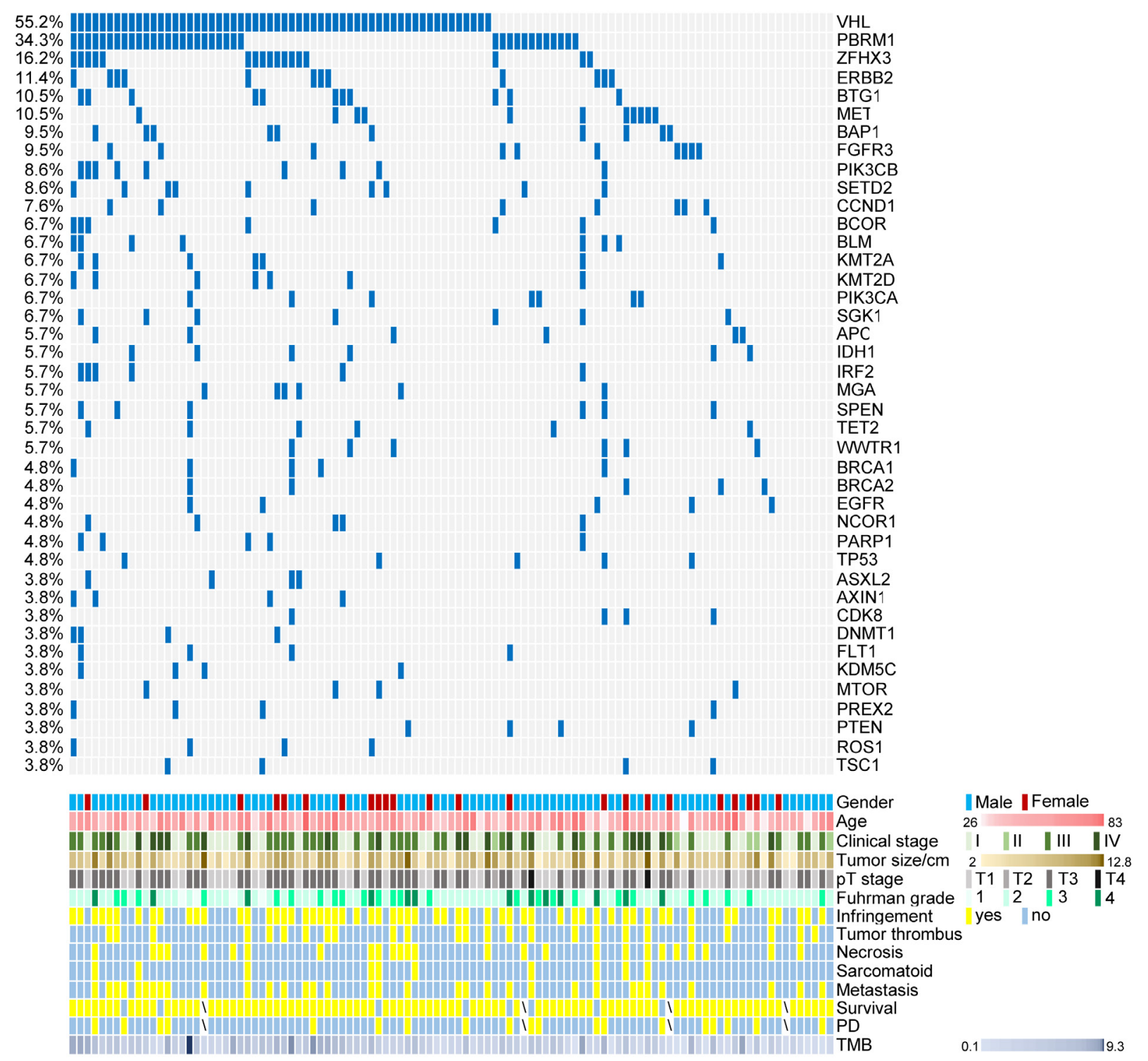

Figure 2 The 41 genes with alteration frequencies $>3 \%$ were used to investigate the relationship between genes and clinical behaviors. Each row represents a gene, each column represents a sample, and blue represents mutation. Gender, age, clinical stage, tumor size, p $\mathrm{T}$ stage, Fuhrman grade, infringement, tumor thrombus, necrosis, sarcomatoid, metastatic disease at diagnosis, survival, PD, and TMB are shown as patient annotations. $\mathrm{PD}$, progressive disease; TMB, tumor mutation burden.

clinical index were used to explore their ability to predict clinical outcomes; as a result, the combinations improved the ability to predict clinical outcomes (Tables 2-6). Among participants with mutated BAP1/PTEN/ERBB2, $61.5 \%$ were metastatic at diagnosis [Table 2; area under the curve (AUC) $=0.694, \mathrm{P}=0.003$, Figure $4 A]$; and patients with mutated $B L M / B T G 1$ had very low risk of metastasis $(6.7 \%)$ (Table 2; $\mathrm{AUC}=0.65, \mathrm{P}=0.064$, Figure $4 B)$. Those with mutated
BAP1/PTEN/TP53 mostly had higher Fuhrman grade $(72.2 \%$, Table 3; AUC $=0.717, \mathrm{P}=0.004$, Figure $4 C)$. Of the participants with mutated BAP1/ERBB2/PARP1, $87.5 \%$ were infringement (Table 4; $\mathrm{AUC}=0.709, \mathrm{P}=0.002$, Figure $4 D$ ), and $92.3 \%$ of patients with mutated BAP1/ $P A R P 1$ had higher tumor node metastasis (TNM) stage (Table 5; AUC $=0.717, \mathrm{P}=0.012$, Figure 4E). However, only $26.3 \%$ of patients with mutated $B A P 1 / M E T$ were 


\begin{tabular}{|c|c|c|c|c|c|c|c|c|c|c|}
\hline TP53 & & & 0.30 & & & & & & & \\
\hline BAP1 & 0.22 & & 0.37 & 0.23 & & 0.23 & 0.23 & & 0.19 & 0.23 \\
\hline PIKЗСB & 0.33 & & & & & & & & & \\
\hline CCND1 & & 0.25 & & & & & & & & \\
\hline WWTR1 & 0.27 & & & & & & & & & \\
\hline MTOR & 0.26 & & & & & & & & & \\
\hline PTEN & & & 0.39 & & 0.24 & & & & 0.18 & \\
\hline BTG1 & & & & & & & & -0.20 & \begin{tabular}{|l|}
-0.17 \\
\end{tabular} & \\
\hline BLM & & & & & & & & & -0.19 & \\
\hline ERBB2 & & & & 0.20 & & & & & 0.20 & \\
\hline PARP1 & & & & 0.20 & & & 0.21 & & & \\
\hline MET & 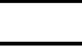 & & . & & . & 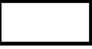 & & 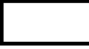 & . & 0.21 \\
\hline
\end{tabular}

Figure 3 Correlation analysis between mutations and clinical indices $(\mathrm{P}<0.1)$. Red, positively correlated; blue, negatively correlated. Number, the correlation coefficients; blank, uncorrelated. pT, pathological T.

Table 2 The relationship between combined genes and metastasis at diagnosis

\begin{tabular}{|c|c|c|c|c|c|}
\hline & \multicolumn{3}{|c|}{ Metastasis at diagnosis } & Phi coefficient & Fisher's $\mathrm{P}$ value \\
\hline BAP1/PTEN/ERBB2 Mut & & & & 0.357 & 0.001 \\
\hline No & 79 & $61 / 79(77.2 \%)$ & $18 / 79(22.8 \%)$ & & \\
\hline Yes & 26 & $10 / 26(38.5 \%)$ & $16 / 26(61.5 \%)$ & & \\
\hline No & 90 & $57 / 90(63.3 \%)$ & $33 / 90(36.7 \%)$ & & \\
\hline Yes & 15 & $14 / 15(93.3 \%)$ & $1 / 15(6.7 \%)$ & & \\
\hline
\end{tabular}

Mut, mutation.

Table 3 The relationship between combined genes and Fuhrman grade

\begin{tabular}{lcccccc}
\hline & \multicolumn{5}{c}{ Fuhrman grade } & Phi coefficient \\
\cline { 2 - 6 } & Total $(\mathrm{n}=105)$ & $1(\mathrm{n}=5)$ & $2(\mathrm{n}=62)$ & $3(\mathrm{n}=25)$ & $4(\mathrm{n}=13)$ & 0.466 \\
\hline BAP1/PTEN/TP53 Mut & & & & & $<0.001$ \\
No & 87 & $5 / 87(5.7 \%)$ & $57 / 87(65.5 \%)$ & $20 / 87(23.0 \%)$ & $5 / 87(5.7 \%)$ & \\
Yes & 18 & $0 / 18(0 \%)$ & $5 / 18(27.8 \%)$ & $5 / 18(27.8 \%)$ & $8 / 18(44.4 \%)$ & \\
\hline
\end{tabular}

Mut, mutation. 
Table 4 The relationship between combined genes and infringement

\begin{tabular}{lcccc}
\hline & \multicolumn{3}{c}{ Infringement } & Phi coefficient \\
\cline { 2 - 3 } & Total $(\mathrm{n}=105)$ & No $(\mathrm{n}=47)$ & Yes $(\mathrm{n}=58)$ & 0.353 \\
\hline BAP1/ERBB2/PARP1 Mut & & & \\
No & 81 & $44 / 81(54.3 \%)$ & $37 / 81(45.7 \%)$ & $<0.001$ \\
Yes & 24 & $3 / 24(12.5 \%)$ & $21 / 24(87.5 \%)$ & \\
\hline
\end{tabular}

Mut, mutation.

Table 5 The relationship between combined genes and pT stage

\begin{tabular}{lcccc}
\hline & \multicolumn{3}{c}{$\mathrm{pT}$ stage } & \multirow{2}{*}{ Phi coefficient } \\
\cline { 2 - 4 } & Total $(\mathrm{n}=105)$ & $\mathrm{T} 1 / \mathrm{T} 2(\mathrm{n}=48)$ & $\mathrm{T} 3 / \mathrm{T} 4(\mathrm{n}=57)$ & 0.287 \\
\hline BAP1/PARP1 Mut & & & \\
No & 92 & $47 / 92(51.1 \%)$ & $45 / 92(48.9 \%)$ & \\
Yes & 13 & $1 / 13(7.7 \%)$ & $12 / 13(92.3 \%)$ & \\
\hline
\end{tabular}

pT, pathological T; Mut, mutation.

Table 6 The relationship between combined genes and sarcomatoid

\begin{tabular}{|c|c|c|c|c|c|}
\hline & \multicolumn{3}{|c|}{ Sarcomatoid } & Phi coefficient & Fisher's $P$ value \\
\hline BAP1/MET Mut & & & & 0.269 & 0.016 \\
\hline No & 96 & $81 / 96(84.4 \%)$ & $5 / 96(5.2 \%)$ & & \\
\hline Yes & 19 & $14 / 19$ (73.7\%) & $5 / 19$ (26.3\%) & & \\
\hline
\end{tabular}

Mut, mutation.

sarcomatoid type (Table 6; AUC $=0.603, \mathrm{P}=0.163$, Figure $4 F$ ). Of the participants with mutated PTEN, 75\% had tumor thrombus (AUC $=0.766, \mathrm{P}=0.072$, Figure $4 G$ ). None of the patients with mutated $B T G 1$ were of the necrosis type (AUC $=0.638, \mathrm{P}=0.135$, Figure $4 H$ ).

\section{The relationship between genetic alterations/clinical indices and survival of ccRCC patients}

Survival analysis was conducted to explore the relationships between DFS and clinical indices, individual genes with alteration frequencies $>3 \%$, and the potential predictors of clinical outcomes.

As shown in Figure $5 A, B$, higher Fuhrman grade and metastasis at diagnosis were associated with poorer prognosis $(\mathrm{P}<0.05)$. Necrosis, high clinical stage, high
TNM stage, and sarcomatoid appeared to be associated with poor prognosis, but not at a statistically significant level (Figure S1A,B,C,D). Age, gender, infringement, and tumor thrombus were not associated with prognosis (Figure S1E,F,G,H).

The Kaplan Meier curves of patients stratified by genes with or without mutation showed that participants with mutations in TP53, CDK8, and TSC1 had a poorer prognosis $(\mathrm{P}<0.05$, Figure $5 C, D, E)$. Mutations in SETD2, SPEN, BAP1, ERBB2, and PIK3CB also showed associations with poor prognosis, but they were not statistically significant (Figure S2). Several genes seemed to be associated with a better prognosis, including VHL, BTG1, and MET; however, they were not statistically significant (Figure S2).

Moreover, relationships between the combination 

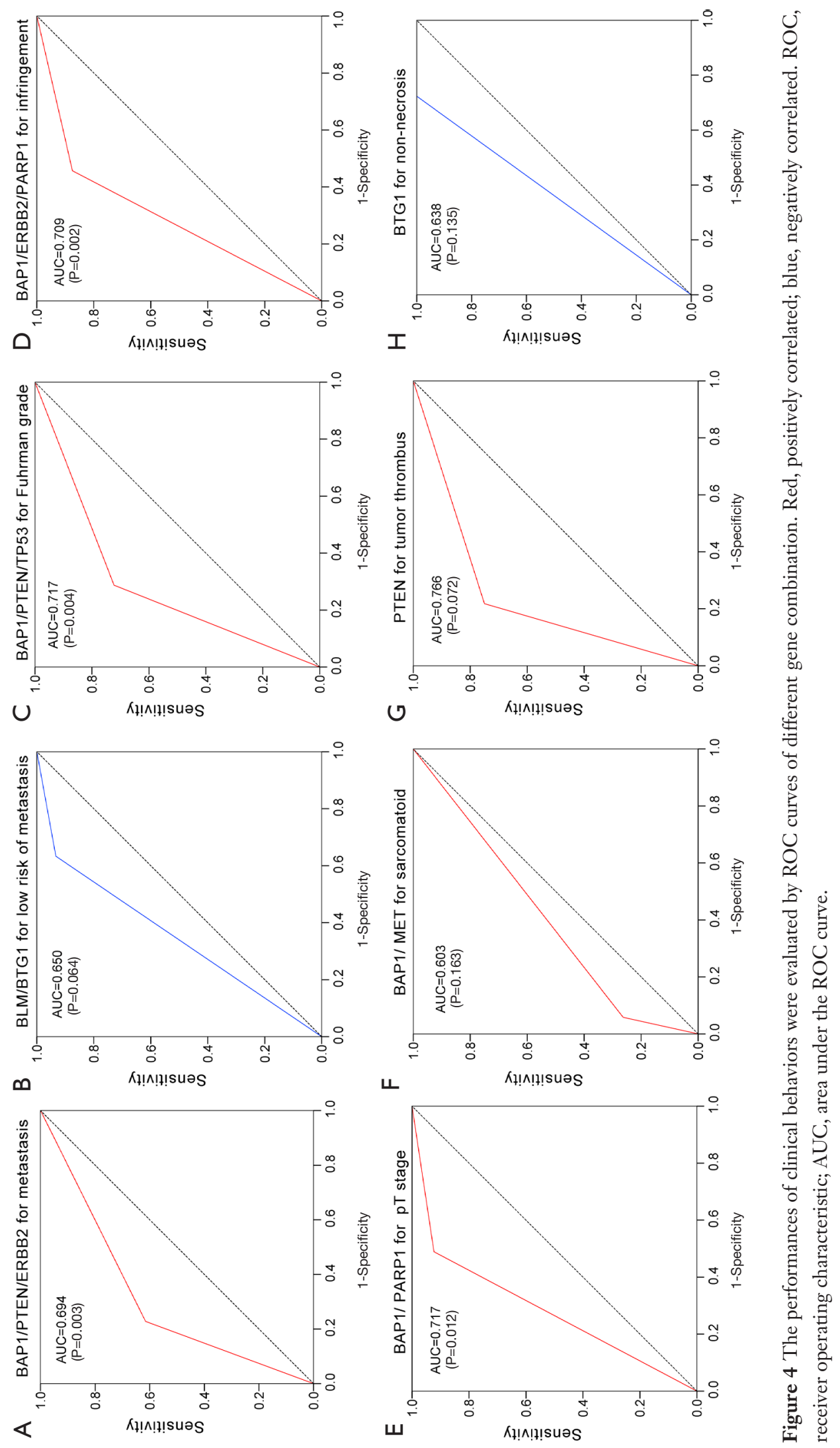

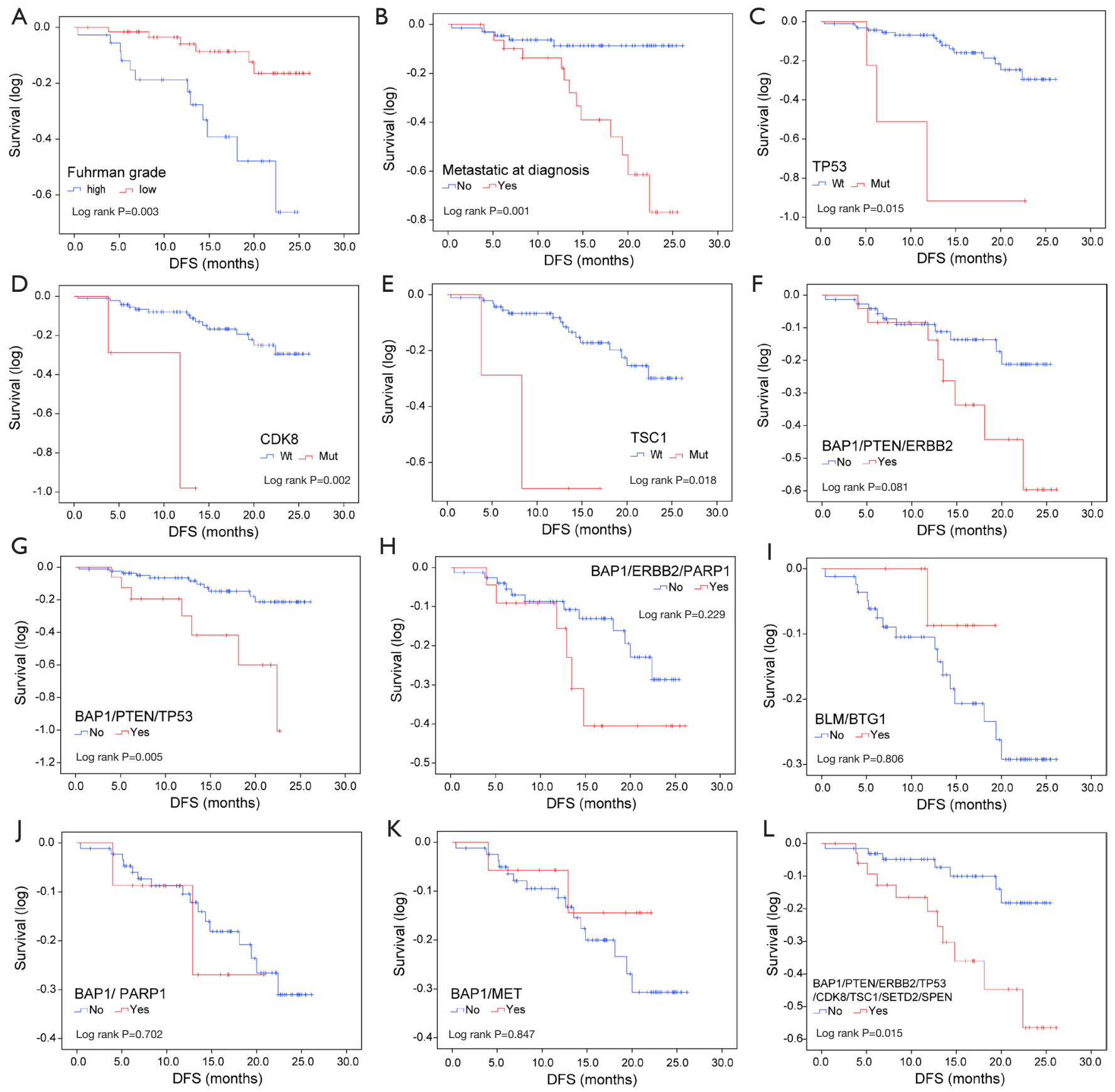

Figure 5 The relationship between genetic alterations/clinical indices and survival of ccRCC patients. (A,B) Kaplan-Meier curves for DFS of Chinese ccRCC patients with different clinical behaviors, (C,D,E) individual mutated genes, (F,G,H,I,J,K) combined genes associated with clinical behaviors, (L) combination of genes associated with poor prognosis. DFS, disease-free survival; ccRCC, clear cell renal cell carcinoma. 
of genes and DFS were analyzed. As shown in Figure $5 F, G, H, I, \mathcal{F}, K$, the predictors of metastasis at prognosis (mutant BAP1/PTEN/ERBB2) and the predictors of higher Fuhrman grade (mutant BAP1/PTEN/TP53) were associated with poor prognosis $(\mathrm{P}<0.1)$. The predictors of infringement (BAP1/ERBB2/PARP1) appeared to be associated with poor prognosis, and the predictors of low risk of metastasis at prognosis (BLM/BTG1) appeared to be associated with better prognosis, but this association was not statistically significant. However, the predictors of higher TNM stage (BAP1/PARP1) and sarcomatoid (BAP1/ $M E T)$ were not associated with DFS.

Furthermore, we combined the predictors of metastasis at prognosis (BAP1/PTEN/ERBB2) and higher Fuhrman grade (BAP1/PTEN/TP53) with genes associated with prognosis, including TP53, CDK8, TSC1, SETD2, and $S P E N$, and analyzed their accumulated association with DFS. As shown in Figure $5 L$, patients with mutations of $\geq 1$ of these genes (BAP1, PTEN, ERBB2, TP53, CDK8, TSC1, $S E T D 2$, and $S P E N)$ had poor prognosis $(\mathrm{P}=0.015)$. The mutations of genes associated with prognosis of Chinese ccRCC were listed in Table S18.

We applied the TCGA-KIRC cohort to validate our findings. For the 8 genes associated with poor prognosis, similar mutation frequencies were seen in our cohort (Figure 2) and the TCGA-KIRC cohort (Figure S3), and their combination was significantly associated with poor prognosis $(\mathrm{P}=0.017)$, suggesting that these genes could predict the poor prognosis. The mutation frequencies of $B T G 1$ and $B L M$ were much higher in our cohort $(10.5 \%$ and $6.7 \%$, respectively) (Figure 2) than they were in the TCGA-KIRC cohort $(0.6 \%$ and $1.5 \%$, respectively) (Figure S4A), and the results of survival analysis were comparable (Figure 5I, Figure S2, Figure S4B,C,D), showing that patients with mutant BTG1 had a better prognosis.

\section{Discussion}

In this study, we enrolled 105 patients with ccRCC and investigated the interrelationships between different clinical indices, the relationships between genetic alterations and clinical indices, and the relationships between clinical indices/genetic alterations with DFS. The results showed that the clinical indices were interrelated (Figure 1), but only Fuhrman grade and metastasis were significantly associated with DFS (Figure $5 A, B$ ). A total of 12 genes were correlated with clinical indices (Figure 3), and the combinations of genes were shown to predict clinical outcomes (Figure 4). Several genes were significantly associated with DFS (Figure $5 C, D, E, G$ ). Finally, a series of genes were proposed to have the potential to predict poor prognosis of ccRCC patients.

Most patients with tumor thrombus $(96.0 \%)$, necrosis $(80.8 \%)$, sarcomatoid $(100 \%)$, metastasis at diagnosis (88.2\%), or high Fuhrman grade (73.7\%) had infringement, while only $41.1 \%, 36.2 \%, 17.2 \%, 51.7 \%$, and $48.3 \%$ of patients with infringement had tumor thrombus, necrosis, sarcomatoid, metastasis at diagnosis, and high Fuhrman grade, respectively, indicating that infringement is not able to predict other clinical outcomes except for high stages (Tables S1-S7). High Fuhrman grade (grade 4) was usually accompanied by infringement (92.3\%), metastasis at diagnosis $(69.2 \%)$, necrosis $(76.9 \%)$, and high stages $(92.3 \%)$, while it was not associated with tumor thrombus or sarcomatoid. The interactions of different clinical indices are shown in Figure S5. Together with the results of survival analysis (Figure 5A,B, Figure S1), Fuhrman grade and metastasis had the most clinical relevance, while infringement had little clinical relevance. Besides Fuhrman grade and metastasis, necrosis, high stages, or sarcomatoid may be also associated with poor prognosis, although they were not significantly associated, possibly due to our relatively small sample size.

The clinicopathological significance of several genes was found. As a well-known gene in ccRCC (9,15-19), BAP1 was found to be frequently mutated in females, patients with high Fuhrman grade, infringement, high stages, metastatic disease at diagnosis, and sarcomatoid lesions, but it was not significantly associated with poor prognosis (Figure S2). However, when BAP1 was combined with other genes, it showed a significant association with poor prognosis (Figure 5G,L), indicating that $B A P 1$ was not the sole factor of poor prognosis. Another well studied gene in ccRCC, PBRM1, was reported to be associated with a better prognosis $(9,20-25)$, while in other reports, it was not associated with survival $(8,26-28)$. Our results showed that PBRM1 was not associated with any clinical indices or DFS (Figure S2). It has been reported that SETD2 is associated with a higher risk of disease recurrence and a shorter survival in ccRCC $(16,29)$. In our study, the associations between SETD2 and clinical indices were not found, but mutant SETD2 was associated with shorter DFS (Figure S2). A previous study of chromophobe RCC showed that alterations in TP53 and PTEN were associated with poor overall survival (OS), and these alterations were more 
frequently observed in metastatic tissue samples compared with matched $\mathrm{pT}$ samples, suggesting a notable role in metastatic progression (30). In our study, TP53 and PTEN were found to be significantly related to high Fuhrman grade, and PTEN was also significantly related to tumor thrombus and metastasis (Figure 3). Moreover, TP53 and $P T E N$ were associated with poor prognosis of patients with ccRCC (Figure 5C,G,L). Furthermore, we integrated the genes that were associated with prognosis, and studied the relationship between mutation status and DFS. The result showed a significant association between genes and DFS (Figure 5L), consistent with results of the TCGA cohort (Figure S6).

In addition, we found $B T G 1$ was negatively related to necrosis and metastatic disease at diagnosis (Figure 3), and it seemed to be associated with a better prognosis (Figure S2), which was consistent with results of the TCGA cohort (Figure S4B). However, BTG1 was not significantly associated with prognosis in either of the 2 cohorts. As shown, the mutation frequency of BTG1 was much higher in Chinese ccRCC participants $(10.5 \%)$ than that in the TCGA cohort $(0.60 \%)$. We suppose that mutation of BTG1 may be specific to Chinese ccRCC and may be a good prognostic factor of ccRCC. A larger Chinese ccRCC cohort is needed to conduct a comprehensive and in-depth study of BTG1.

The function of the eight genes, which were found to be associated with poor prognosis of Chinese ccRCC in this study, has been elucidated in the literatures. TP5 3 and PTEN are well known tumor suppressor genes that slow down cell division, repair DNA mistakes, or participate in the process of apoptosis or programmed cell death (7). $B A P 1$, a H2A deubiquitinase, and SETD2, a histone $\mathrm{H} 3$ lysine 36 trimethylating enzyme are involved in chromosome remodelling. BAP1 participates in homologous recombination (HR) repair and prevents chromosomal instability through modulation of various substrates, including MCRS1 and INO80. SETD2 contributes to the maintenance of genome integrity through suppression of replication stress and promotion of HR repair, and contributes to DDR. ERBB2, a member of the epidermal growth factor receptor (EGFR) family with intrinsic protein tyrosine kinase activity, is involved in signal transduction, cell proliferation, development, differentiation, migration and tumor formation (31). CDK8 is a nuclear serinethreonine kinase that functions as a transcriptional regulator. TSC1 is a component of TSC complex that is implicated as a tumor suppressor and negatively regulates
mTORC1 signaling (32). SPEN encodes a hormone inducible transcriptional repressor, with essential regulatory roles in transcriptional repression (33). BTG1, which might be associated with good prognosis of Chinese ccRCC, may inhibit cell growth and promote apoptosis by interacting with PRMT1 in RCC (34).

\section{Conclusions}

A total of 8 genes (BAP1, PTEN, ERBB2, TP53, CDK8, TSC1, SETD2, and SPEN) were found to be associated with poor prognosis of Chinese ccRCC, and a new gene (BTG1) was possibly associated with good prognosis of Chinese ccRCC.

\section{Acknowledgments}

Funding: This work was supported by National Nature Science Foundation of China (81972381, 82070778). We would like to thank Shanghai Tongshu Biotechnology Co., Ltd. for technical support, and all participants for their kind cooperation in this study.

\section{Footnote}

Reporting Checklist: The authors have completed the REMARK reporting checklist. Available at http://dx.doi. org/10.21037/tau-20-1410

Data Sharing Statement: Available at http://dx.doi. org/10.21037/tau-20-1410

Conflicts of Interest: All authors have completed the ICMJE uniform disclosure form (available at http://dx.doi. org/10.21037/tau-20-1410). The authors have no conflicts of interest to declare.

Ethical Statement: The authors are accountable for all aspects of the work in ensuring that questions related to the accuracy or integrity of any part of the work are appropriately investigated and resolved. All procedures performed in this study involving human participants were in accordance with the Declaration of Helsinki (as revised in 2013). This study was approved by Peking University Third Hospital Medical Science Research Ethics Committee (No. M2018042). Written informed consent was provided by all participants.

Open Access Statement: This is an Open Access article 
distributed in accordance with the Creative Commons Attribution-NonCommercial-NoDerivs 4.0 International License (CC BY-NC-ND 4.0), which permits the noncommercial replication and distribution of the article with the strict proviso that no changes or edits are made and the original work is properly cited (including links to both the formal publication through the relevant DOI and the license). See: https://creativecommons.org/licenses/by-nc-nd/4.0/.

\section{References}

1. Bray F, Ferlay J, Soerjomataram I, et al. Global cancer statistics 2018: GLOBOCAN estimates of incidence and mortality worldwide for 36 cancers in 185 countries. CA Cancer J Clin 2018;68:394-424.

2. Escudier B, Porta C, Schmidinger M, et al. Renal cell carcinoma: ESMO Clinical Practice Guidelines for diagnosis, treatment and follow-upt. Ann Oncol 2019;30:706-20.

3. Motzer RJ, Bacik J, Murphy BA, et al. Interferon-alfa as a comparative treatment for clinical trials of new therapies against advanced renal cell carcinoma. J Clin Oncol 2002;20:289-96.

4. Voss MH, Reising A, Cheng Y, et al. Genomically annotated risk model for advanced renal-cell carcinoma: a retrospective cohort study. Lancet Oncol 2018;19:1688-98.

5. Kim WY, Kaelin WG. Role of VHL gene mutation in human cancer. J Clin Oncol 2004;22:4991-5004.

6. Rini BI, Escudier B, Tomczak P, et al. Comparative effectiveness of axitinib versus sorafenib in advanced renal cell carcinoma (AXIS): a randomised phase 3 trial. Lancet 2011;378:1931-9.

7. Wang L, Cai W, Kong W, et al. Plasma fibrinogen as prognostic predictor in patients with metastatic renal cell carcinoma receiving target therapy. Transl Cancer Res 2018;7:1384-92.

8. Hakimi AA, Chen YB, Wren J, et al. Clinical and pathologic impact of select chromatin-modulating tumor suppressors in clear cell renal cell carcinoma. Eur Urol 2013;63:848-54.

9. Gossage L, Murtaza M, Slatter AF, et al. Clinical and pathological impact of VHL, PBRM1, BAP1, SETD2, KDM6A, and JARID1c in clear cell renal cell carcinoma. Genes Chromosomes Cancer 2014;53:38-51.

10. Mendoza-Alvarez A, Guillen-Guio B, Baez-Ortega A, et al. Whole-Exome Sequencing Identifies Somatic Mutations Associated With Mortality in Metastatic Clear Cell Kidney Carcinoma. Front Genet 2019;10:439.
11. Jin B, Wang Y, Luo J, et al. Comprehensive genomic profiling in Chinese patients with clear cell renal cell carcinoma. J Clin Oncol 2018;36:e13517.

12. Wang J, Xi Z, Xi J, et al. Somatic mutations in renal cell carcinomas from Chinese patients revealed by whole exome sequencing. Cancer Cell Int 2018;18:159.

13. Wang XM, Lu Y, Song YM, et al. Integrative genomic study of Chinese clear cell renal cell carcinoma reveals features associated with thrombus. Nat Commun 2020;11:739.

14. Lai Z, Markovets A, Ahdesmaki M, et al. VarDict: a novel and versatile variant caller for next-generation sequencing in cancer research. Nucleic Acids Res 2016;44:e108.

15. Peña-Llopis S, Vega-Rubín-de-Celis S, Liao A, et al. BAP1 loss defines a new class of renal cell carcinoma. Nat Genet 2012;44:751-9.

16. Hakimi AA, Ostrovnaya I, Reva B, et al. Adverse outcomes in clear cell renal cell carcinoma with mutations of 3 p2 1 epigenetic regulators BAP1 and SETD2: a report by MSKCC and the KIRC TCGA research network. Clin Cancer Res 2013;19:3259-67.

17. Kapur P, Peña-Llopis S, Christie A, et al. Effects on survival of BAP1 and PBRM1 mutations in sporadic clearcell renal-cell carcinoma: a retrospective analysis with independent validation. Lancet Oncol 2013;14:159-67.

18. Joseph RW, Kapur P, Serie DJ, et al. Loss of BAP1 protein expression is an independent marker of poor prognosis in patients with low-risk clear cell renal cell carcinoma. Cancer 2014;120:1059-67.

19. Park JS, Lee HJ, Cho NH, et al. Risk Prediction Tool for Aggressive Tumors in Clinical T1 Stage Clear Cell Renal Cell Carcinoma Using Molecular Biomarkers. Comput Struct Biotechnol J 2019;17:371-7.

20. Fay AP, de Velasco G, Ho TH, et al. Whole-Exome Sequencing in Two Extreme Phenotypes of Response to VEGF-Targeted Therapies in Patients With Metastatic Clear Cell Renal Cell Carcinoma. J Natl Compr Canc Netw 2016;14:820-4.

21. Ho TH, Choueiri TK, Wang K, et al. Correlation Between Molecular Subclassifications of Clear Cell Renal Cell Carcinoma and Targeted Therapy Response. Eur Urol Focus 2016;2:204-9.

22. Hsieh JJ, Chen D, Wang PI, et al. Genomic Biomarkers of a Randomized Trial Comparing First-line Everolimus and Sunitinib in Patients with Metastatic Renal Cell Carcinoma. Eur Urol 2017;71:405-14.

23. McDermott DF, Huseni MA, Atkins MB, et al. Clinical activity and molecular correlates of response to 
atezolizumab alone or in combination with bevacizumab versus sunitinib in renal cell carcinoma. Nat Med 2018;24:749-57.

24. Miao D, Margolis CA, Gao W, et al. Genomic correlates of response to immune checkpoint therapies in clear cell renal cell carcinoma. Science 2018;359:801-6.

25. Abou Alaiwi S, Nassar A, El Bakouny Z, et al. Association of polybromo-associated BAF (PBAF) complex mutations with overall survival (OS) in cancer patients (pts) treated with checkpoint inhibitors (ICIs). J Clin Oncol 2019;37:103.

26. Cancer Genome Atlas Research Network. Comprehensive molecular characterization of clear cell renal cell carcinoma. Nature 2013;499:43-9.

27. Ricketts CJ, De Cubas AA, Fan H, et al. The Cancer Genome Atlas Comprehensive Molecular Characterization of Renal Cell Carcinoma. Cell Rep 2018;23:3698.

28. Hakimi AA, Ged Y, Flynn J, et al. The impact of PBRM1 mutations on overall survival in greater than 2,100 patients treated with immune checkpoint blockade (ICB). J Clin Oncol 2019;37:666.

29. Sato Y, Yoshizato T, Shiraishi Y, et al. Integrated molecular analysis of clear-cell renal cell carcinoma. Nat Genet 2013;45:860-7.

30. Casuscelli J, Weinhold N, Gundem G, et al. Genomic landscape and evolution of metastatic chromophobe renal cell carcinoma. JCI Insight 2017;2:e92688.

31. Weng WH, Chen YT, Yu KJ, et al. Genetic alterations of HER genes in chromophobe renal cell carcinoma. Oncol Lett 2016;11:2111-6.

32. Huang J, Manning BD. The TSC1-TSC2 complex: a molecular switchboard controlling cell growth. Biochem J 2008;412:179-90.

33. Légaré S, Cavallone L, Mamo A, et al. The Estrogen Receptor Cofactor SPEN Functions as a Tumor Suppressor and Candidate Biomarker of Drug Responsiveness in Hormone-Dependent Breast Cancers. Cancer Res 2015;75:4351-63.

34. Liu C, Tao T, Xu B, et al. BTG1 potentiates apoptosis and suppresses proliferation in renal cell carcinoma by interacting with PRMT1. Oncol Lett 2015;10:619-24.

(English Language Editor: J. Jones)
Cite this article as: $\mathrm{Bi} \mathrm{H}$, Yin J, Zhou L, Wu Y, Ge L, Lu M, Liu L, Zhang H, Zhao Y, Liu C, Ma L. Clinicopathological and prognostic impact of somatic mutations in Chinese patients with clear cell renal cell carcinoma. Transl Androl Urol 2020;9(6):2751-2763. doi: 10.21037/tau-20-1410 


\section{Supplementary}

Table S1 The interrelationship between infringement and other clinical indices of ccRCC

\begin{tabular}{|c|c|c|c|c|}
\hline & \multicolumn{2}{|c|}{ Infringement } & Phi coefficient & Fisher's P-value \\
\hline Clinical stage & & & 0.923 & $<0.001$ \\
\hline $\mathrm{I} / \mathrm{II}$ & $45 / 47(95.7 \%)$ & 2/58 (3.4\%) & & \\
\hline III/IV & 2/47 (4.3\%) & $56 / 58(96.6 \%)$ & & \\
\hline $\mathrm{T} 1 / \mathrm{T} 2$ & 46/47 (97.9\%) & 2/58 (3.4\%) & & \\
\hline $\mathrm{T} 3 / \mathrm{T} 4$ & $1 / 47$ (2.1\%) & $56 / 58(96.6 \%)$ & & \\
\hline
\end{tabular}

ccRCC, clear cell renal cell carcinoma; pT, pathological T stage.

Table S2 The interrelationship between Fuhrman grade and other clinical indices of ccRCC

\begin{tabular}{|c|c|c|c|c|c|c|}
\hline & \multicolumn{4}{|c|}{ Fuhrman grade } & Phi coefficient & Fisher's P-value \\
\hline Infringement & & & & & 0.342 & 0.004 \\
\hline No & $4 / 5$ (80.0\%) & $33 / 62(53.2 \%)$ & $9 / 25$ (36.0\%) & $1 / 13(7.7 \%)$ & & \\
\hline Yes & $1 / 5(20.0 \%)$ & $29 / 62(46.8 \%)$ & $16 / 25(64.0 \%)$ & 12/13 (92.3) & & \\
\hline No & $5 / 5(100 \%)$ & $46 / 62(74.2 \%)$ & $16 / 25(64.0 \%)$ & 4/13 (30.8\%) & & \\
\hline Yes & $0 / 5(0 \%)$ & $16 / 62(25.8 \%)$ & $9 / 25$ (36.0\%) & 9/13 (69.2\%) & & \\
\hline Tumor thrombus & & & & & 0.288 & 0.035 \\
\hline No & $5 / 5(100 \%)$ & $50 / 62(80.6 \%)$ & $19 / 25$ (76.0\%) & 6/13 (46.2\%) & & \\
\hline No & 4/5 (80.0\%) & $54 / 62(87.1 \%)$ & $18 / 25$ (72.0\%) & $3 / 13(23.1 \%)$ & & \\
\hline Yes & $1 / 5(20.0 \%)$ & 8/62 (12.9\%) & $7 / 25(28.0 \%)$ & $10 / 13(76.9 \%)$ & & \\
\hline Sarcomatoid & & & & & 0.575 & $<0.001$ \\
\hline No & $5 / 5(100 \%)$ & $61 / 62(98.4 \%)$ & $23 / 25(92.0 \%)$ & $6 / 13(46.2 \%)$ & & \\
\hline Yes & $0 / 5(0 \%)$ & 1/62 (1.6\%) & 2/25 (8.0\%) & 7/13 (53.8\%) & & \\
\hline Clinical stage & & & & & 0.326 & 0.006 \\
\hline $\mathrm{I} / \mathrm{II}$ & $4 / 5(80.0 \%)$ & $32 / 62(51.6 \%)$ & $10 / 25(40.0 \%)$ & $1 / 13(7.7 \%)$ & & \\
\hline III/IV & $1 / 5(20.0 \%)$ & $30 / 62(48.4 \%)$ & $15 / 25(60.0 \%)$ & $12 / 13(92.3 \%)$ & & \\
\hline
\end{tabular}

ccRCC, clear cell renal cell carcinoma; pT, pathological T stage. 
Table S3 The interrelationship between metastatic disease at diagnosis and other clinical indices of ccRCC

\begin{tabular}{lccc}
\hline & \multicolumn{2}{c}{ Metastatic disease at diagnosis } & Phi coefficient \\
\cline { 2 - 4 } & No $(\mathrm{n}=71)$ & Yes $(\mathrm{n}=34)$ & 0.459 \\
\hline Infringement & $43 / 71(60.6 \%)$ & $4 / 34(11.8 \%)$ & $<0.001$ \\
No & $28 / 71(39.4 \%)$ & $30 / 34(88.2 \%)$ & 0.541 \\
Yes & & & $<0.001$ \\
Clinical stage & $45 / 71(63.4 \%)$ & $32 / 34(94.1 \%)$ & 0.512 \\
I/II & $26 / 71(36.6 \%)$ & & $<0.001$ \\
III/IV & & $3 / 34(8.8 \%)$ & $31 / 34(91.2 \%)$ \\
PT & $45 / 71(63.4 \%)$ & & \\
T1/T2 & $26 / 71(36.6 \%)$ & & \\
T3/T4 & & & \\
\hline
\end{tabular}

ccRCC, clear cell renal cell carcinoma; pT, pathological T stage.

Table S4 The interrelationship between tumor thrombus and other clinical indices of ccRCC

\begin{tabular}{|c|c|c|c|c|}
\hline & \multicolumn{2}{|c|}{ Tumor thrombus } & Phi coefficient & Fisher's P-value \\
\hline Infringement & & & 0.458 & $<0.001$ \\
\hline No & $46 / 80(57.5 \%)$ & $1 / 25(4.0 \%)$ & & \\
\hline Yes & $34 / 80(42.5 \%)$ & $24 / 25$ (96.0\%) & & \\
\hline No & $66 / 80(82.5 \%)$ & $5 / 25(20.0 \%)$ & & \\
\hline Yes & $14 / 80(17.5 \%)$ & 20/25 (80.0\%) & & \\
\hline Necrosis & & & 0.249 & 0.016 \\
\hline No & $65 / 80(81.3 \%)$ & $14 / 25(56.0 \%)$ & & \\
\hline $\mathrm{I} / \mathrm{II}$ & $46 / 80(57.5 \%)$ & $1 / 25(4.0 \%)$ & & \\
\hline III/IV & $34 / 80(42.5 \%)$ & $24 / 25(96.0 \%)$ & & \\
\hline pT & & & 0.468 & $<0.001$ \\
\hline $\mathrm{T} 1 / \mathrm{T} 2$ & $47 / 80(58.8 \%)$ & $1 / 25(4.0 \%)$ & & \\
\hline $\mathrm{T} 3 / \mathrm{T} 4$ & $33 / 80(41.3 \%)$ & $24 / 25$ (96.0\%) & & \\
\hline
\end{tabular}

ccRCC, clear cell renal cell carcinoma; pT, pathological T stage. 
Table S5 The interrelationship between necrosis and other clinical indices of ccRCC

\begin{tabular}{|c|c|c|c|c|}
\hline & \multicolumn{2}{|c|}{ Necrosis } & Phi coefficient & Fisher's P-value \\
\hline Infringement & & & 0.295 & 0.003 \\
\hline No & $42 / 79(53.2 \%)$ & $5 / 26(19.2 \%)$ & & \\
\hline Yes & $37 / 79(46.8 \%)$ & $21 / 26(80.8 \%)$ & & \\
\hline No & $61 / 79(77.2 \%)$ & $10 / 26$ (38.5\%) & & \\
\hline Yes & $18 / 79(22.8 \%)$ & $16 / 26(61.5 \%)$ & & \\
\hline Clinical stage & & & 0.339 & 0.001 \\
\hline I/II & $43 / 79(54.4 \%)$ & 4/26 (15.4\%) & & \\
\hline $\mathrm{T} 1 / \mathrm{T} 2$ & $44 / 79(55.7 \%)$ & $4 / 26(15.4 \%)$ & & \\
\hline T3/T4 & $35 / 79$ (44.3\%) & 22/26 (84.6\%) & & \\
\hline
\end{tabular}

ccRCC, clear cell renal cell carcinoma; pT, pathological T stage.

Table S6 The interrelationship between sarcomatoid and other clinical indices of ccRCC

\begin{tabular}{|c|c|c|c|c|}
\hline & \multicolumn{2}{|c|}{ Sarcomatoid } & Phi coefficient & Fisher's P-value \\
\hline Infringement & & & 0.292 & 0.002 \\
\hline No & 47/95 (49.5\%) & $0 / 10(0 \%)$ & & \\
\hline Yes & 48/95 (50.5\%) & $10 / 10(100.0 \%)$ & & \\
\hline No & 69/95 (72.6\%) & 2/10 (20.0\%) & & \\
\hline Yes & 26/95 (27.4\%) & 8/10 (80.0\%) & & \\
\hline Necrosis & & & 0.415 & $<0.001$ \\
\hline No & 77/95 (81.1\%) & 2/10 (20.0\%) & & \\
\hline $\mathrm{I} / \mathrm{II}$ & 47/95 (49.5\%) & $0 / 10(0 \%)$ & & \\
\hline III/IV & 48/95 (50.5\%) & $10 / 10(100.0 \%)$ & & \\
\hline pT & & & 0.298 & 0.002 \\
\hline $\mathrm{T} 1 / \mathrm{T} 2$ & 48/95 (50.5\%) & $0 / 10(0 \%)$ & & \\
\hline T3/T4 & 47/95 (49.5\%) & $10 / 10(100.0 \%)$ & & \\
\hline
\end{tabular}

ccRCC, clear cell renal cell carcinoma; pT, pathological T stage. 
Table S7 The interrelationship between gender and age of ccRCC

\begin{tabular}{lccc}
\hline & \multicolumn{2}{c}{ Gender } & Phi coefficient \\
\cline { 2 - 4 } & Male $(\mathrm{n}=82)$ & Female $(\mathrm{n}=23)$ & 0.245 \\
\hline Age & & & 0.017 \\
$<58$ & $42 / 82(51.2 \%)$ & $5 / 23(21.7 \%)$ & $18 / 23(78.3 \%)$ \\
\hline 58 & $40 / 82(48.8 \%)$ & & \\
\hline
\end{tabular}

ccRCC, clear cell renal cell carcinoma.

Table S8 The relationship between individual genes and gender

\begin{tabular}{|c|c|c|c|c|}
\hline & \multicolumn{2}{|c|}{ Gender } & Phi coefficient & Fisher's P-value \\
\hline BAP1 & & & 0.220 & 0.039 \\
\hline WT & 77/82 (93.9\%) & 18/23 (78.3\%) & & \\
\hline Mut & $5 / 82(6.1 \%)$ & $5 / 23(21.7 \%)$ & & \\
\hline WT & 79/82 (96.3\%) & 17/23 (73.9\%) & & \\
\hline Mut & $3 / 82(3.7 \%)$ & $6 / 23(26.1 \%)$ & & \\
\hline WWTR1 & & & 0.266 & 0.02 \\
\hline WT & $80 / 82(97.6 \%)$ & 19/23 (82.6\%) & & \\
\hline WT & 81/82 (98.8\%) & 20/23 (87.0\%) & & \\
\hline Mut & $1 / 82(1.2 \%)$ & $3 / 23(13.0 \%)$ & & \\
\hline
\end{tabular}

WT, wild type; Mut, mutant. 
Table S9 The relationship between individual genes and Fuhrman grade

\begin{tabular}{|c|c|c|c|c|c|c|}
\hline & \multicolumn{4}{|c|}{ Fuhrman grade } & Phi coefficient & Fisher's P-value \\
\hline TP53 & & & & & 0.296 & 0.067 \\
\hline WT & $5 / 5(100 \%)$ & 61/62 (98.4\%) & $21 / 25$ (84.0\%) & 13/13 (100\%) & & \\
\hline Mut & $0 / 5(0 \%)$ & 1/62 (1.6\%) & 4/25 (16.0\%) & 0/13 (0\%) & & \\
\hline WT & $5 / 5(100 \%)$ & $58 / 62(93.5 \%)$ & $24 / 25$ (96.0\%) & 8/13 (61.5\%) & & \\
\hline Mut & 0/5 (0\%) & 4/62 (6.5\%) & $1 / 25(4.0 \%)$ & $5 / 13(38.5 \%)$ & & \\
\hline PTEN & & & & & 0.388 & 0.004 \\
\hline WT & $5 / 5(100 \%)$ & 62/62 (100\%) & $24 / 25(96.0 \%)$ & 10/13 (76.9\%) & & \\
\hline
\end{tabular}

WT, wild type; Mut, mutant.

Table S10 The relationship between individual genes and infringement

\begin{tabular}{lccc}
\hline & & Infringement & Phi coefficient \\
\cline { 2 - 3 } BAP1 & No $(\mathrm{n}=47)$ & Yes $(\mathrm{n}=58)$ & 0.227 \\
WT & $46 / 47(97.9 \%)$ & $49 / 58(84.5 \%)$ & 0.022 \\
Mut & $1 / 47(2.1 \%)$ & $9 / 58(15.5 \%)$ & 0.203 \\
ERBB2 & & & 0.061 \\
WT & $45 / 47(95.7 \%)$ & $48 / 58(82.8 \%)$ & 0.201 \\
Mut & $2 / 47(4.3 \%)$ & $10 / 58(17.2 \%)$ & 0.063 \\
PARP1 & & $53 / 58(91.4 \%)$ & $5 / 58(8.6 \%)$ \\
WT & $47 / 47(100 \%)$ & & \\
Mut & $0 / 47(0 \%)$ & & \\
\hline
\end{tabular}

WT, wild type; Mut, mutant. 
Table S11 The relationship between individual genes and metastasis at diagnosis

\begin{tabular}{|c|c|c|c|c|}
\hline & \multicolumn{2}{|c|}{ Metastasis at diagnosis } & Phi coefficient & Fisher's P-value \\
\hline PTEN & & & 0.181 & 0.099 \\
\hline WT & $70 / 71(98.6 \%)$ & $31 / 34(91.2 \%)$ & & \\
\hline Mut & $1 / 71(1.4 \%)$ & $3 / 34(8.8 \%)$ & & \\
\hline WT & $61 / 71(85.9 \%)$ & $33 / 34(97.1 \%)$ & & \\
\hline Mut & $10 / 71(14.1 \%)$ & $1 / 34(2.9 \%)$ & & \\
\hline BLM & & & -0.185 & 0.093 \\
\hline WT & $64 / 71(90.1 \%)$ & $34 / 34(100 \%)$ & & \\
\hline WT & 67/71 (94.4\%) & 28/34 (82.4\%) & & \\
\hline Mut & $4 / 71(5.6 \%)$ & 6/34 (17.6\%) & & \\
\hline ERBB2 & & & 0.199 & 0.053 \\
\hline WT & 66/71 (93.0\%) & $27 / 34(79.4 \%)$ & & \\
\hline Mut & $5 / 71(7.0 \%)$ & $7 / 34$ (20.6\%) & & \\
\hline
\end{tabular}

WT, wild type; Mut, mutant.

Table S12 The relationship between individual genes and $\mathrm{pT}$ stage

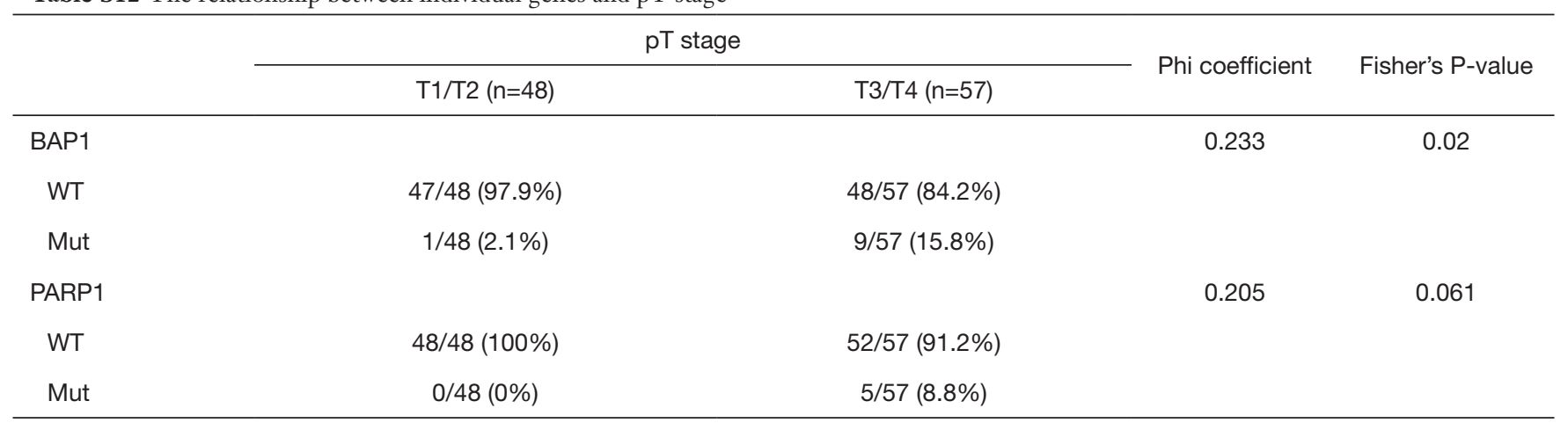

WT, wild type; Mut, mutant. 
Table S13 The relationship between individual genes and sarcomatoid

\begin{tabular}{cccc}
\hline & \multicolumn{2}{c}{ Sarcomatoid } & Phi coefficient \\
\cline { 2 - 3 } BAP1 & No $(\mathrm{n}=95)$ & Yes $(\mathrm{n}=10)$ & 0.226 \\
WT & & & \\
Mut & $88 / 95(92.6 \%)$ & $3 / 10(70.0 \%)$ & 0.053 \\
MET & $7 / 95(7.4 \%)$ & & 0.207 \\
WT & & $7 / 10(70.0 \%)$ & 0.069 \\
Mut & $87 / 95(91.6 \%)$ & $3 / 10(30.0 \%)$ & \\
\hline
\end{tabular}

WT, wild type; Mut, mutant.

Table S14 The relationship between individual genes and clinical stage

\begin{tabular}{|c|c|c|c|c|}
\hline & \multicolumn{2}{|c|}{ Clinical stage } & Phi coefficient & Fisher's P-value \\
\hline BAP1 & & & 0.227 & 0.022 \\
\hline WT & $46 / 47$ (97.9\%) & 49/58 (84.5\%) & & \\
\hline Mut & $1 / 47(2.1 \%)$ & $9 / 58(15.5 \%)$ & & \\
\hline
\end{tabular}

WT, wild type; Mut, mutant.

Table S15 The relationship between individual genes and ages

\begin{tabular}{|c|c|c|c|c|}
\hline & \multicolumn{2}{|c|}{ Age } & Phi coefficient & Fisher's P-value \\
\hline CCND1 & & & 0.247 & 0.021 \\
\hline WT & 57/58 (98.3\%) & $40 / 47(85.1 \%)$ & & \\
\hline Mut & 1/58 (1.7\%) & 7/47 (14.9\%) & & \\
\hline
\end{tabular}

WT, wild type; Mut, mutant. 
Table S16 The relationship between individual genes and tumor thrombus

\begin{tabular}{cccc}
\hline & \multicolumn{2}{c}{ Tumor thrombus } & Phi coefficient \\
\cline { 2 - 4 } & No $(n=80)$ & Fes $(n=25)$ & 0.239 \\
\hline PTEN & & & 0.041 \\
WT & $79 / 80(98.8 \%)$ & $22 / 25(88.0 \%)$ & \\
Mut & $1 / 80(1.2 \%)$ & $3 / 25(12.0 \%)$ & \\
\hline
\end{tabular}

WT, wild type; Mut, mutant.

Table S17 The relationship between individual genes and necrosis

\begin{tabular}{cccc}
\hline & & Necrosis & Phi coefficient \\
\cline { 2 - 3 } & No $(n=79)$ & Yes $(n=26)$ & -0.196 \\
BTG1 & & & 0.062 \\
WT & $68 / 79(86.1 \%)$ & $26 / 26(100 \%)$ & $0 / 26(0 \%)$ \\
Mut & $11 / 79(13.9 \%)$ & 0 & \\
\hline
\end{tabular}

WT, wild type; Mut, mutant. 

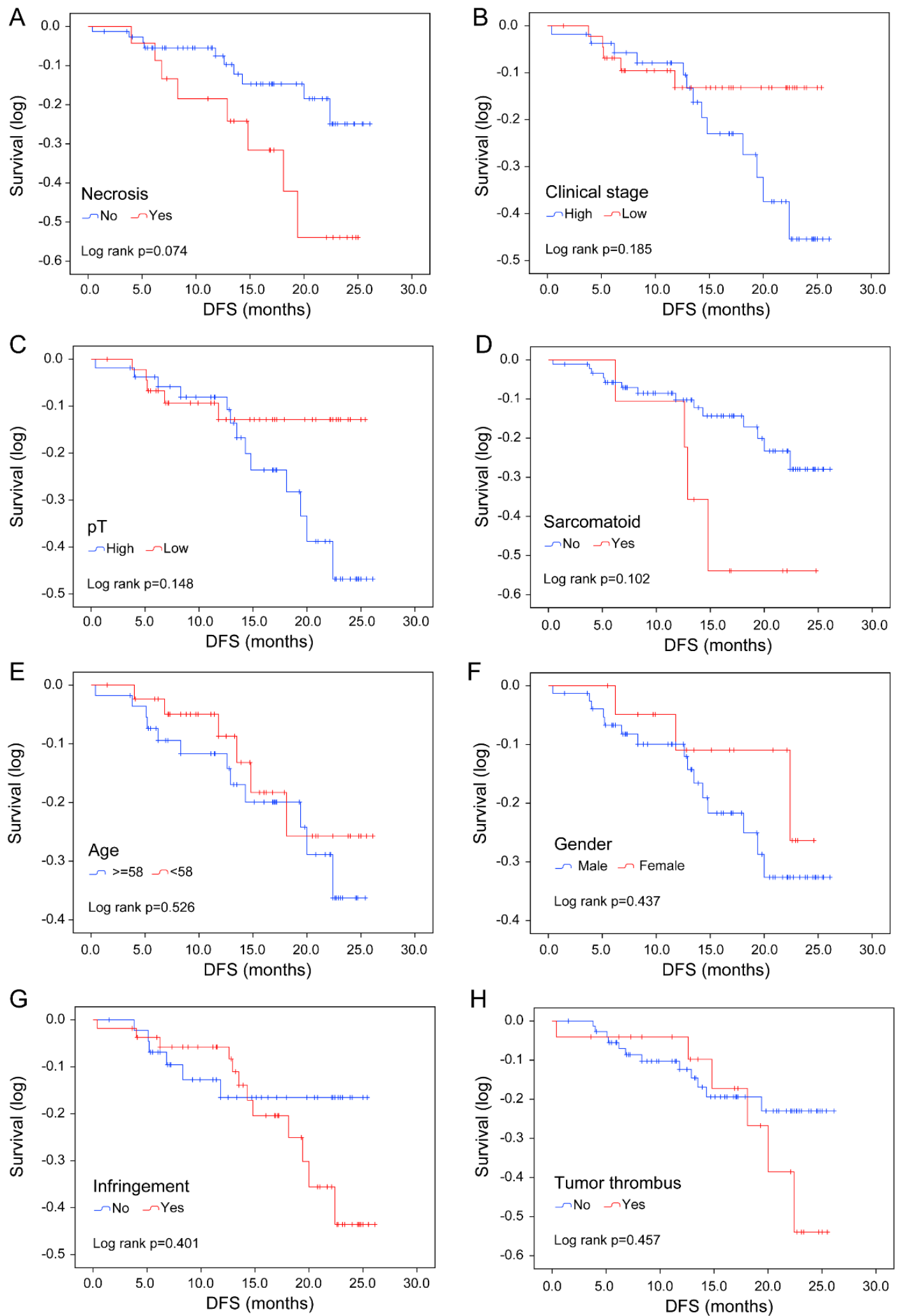

Figure S1 Kaplan-Meier curves for DFS of Chinese ccRCC patients with different clinical features. DFS, disease-free survival; ccRCC, clear cell renal cell carcinoma. 

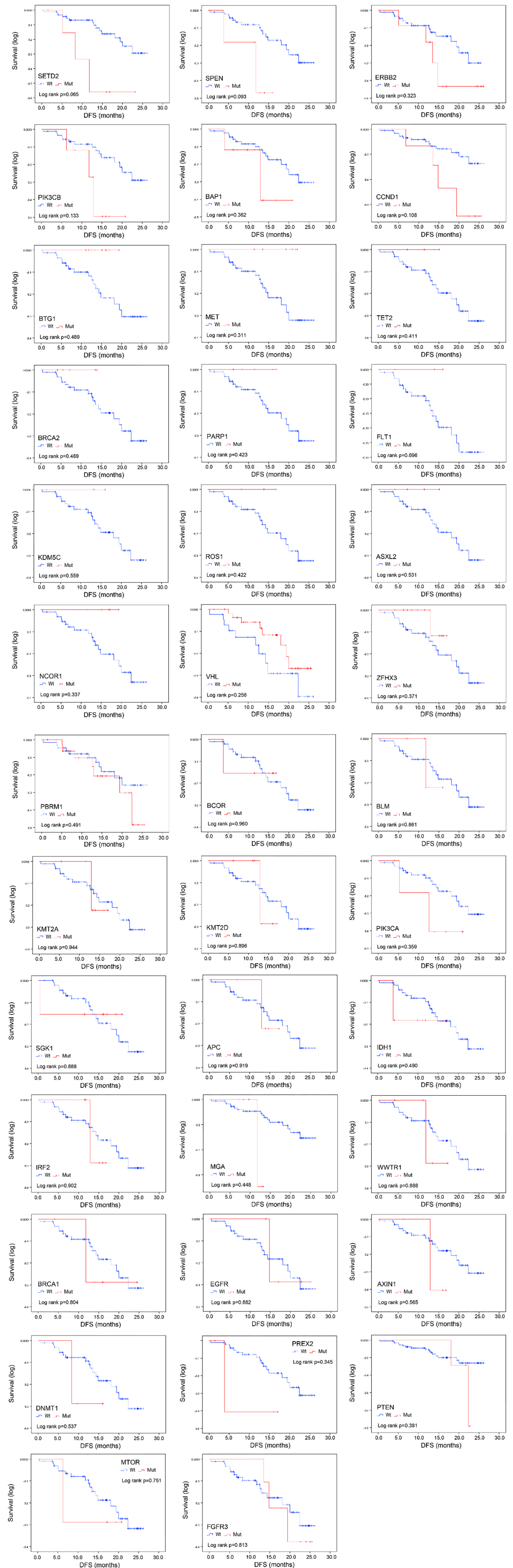

Figure S2 Kaplan-Meier curves for DFS of Chinese ccRCC patients with each mutated gene. DFS, disease-free survival; ccRCC, clear cell cenal cell carcinoma. 
Table S18 The mutations of genes associated with prognosis of Chinese ccRCC

\begin{tabular}{|c|c|}
\hline Genes & Mutations \\
\hline PTEN & p.Y76Mfs`23, p.P246L, p.A151*fs*1, p.L112P, p.L182* \\
\hline ERBB2 & p.A241V, p.V1085L, CNV amplification \\
\hline TP53 & p.R175H, p.R273H, p.G325Ifs*10, p.H168Lfs*5 \\
\hline TSC1 & p.R500*, p.Q527*, p.W1063G, p.R509Q \\
\hline SETD2 & p.Q2484*, p.G704R, p.K568fs, p.W2395*, p.Y480*, p.K568*, p.N1289fs, p.Thr305fs, p.N801Tfs*17 \\
\hline SPEN & p.D3010Y, p.H1165L, p.P2465L, p.E1412K \\
\hline BTG1 & p.G64R \\
\hline
\end{tabular}


Altered in $94(27.98 \%)$ of 336 samples.

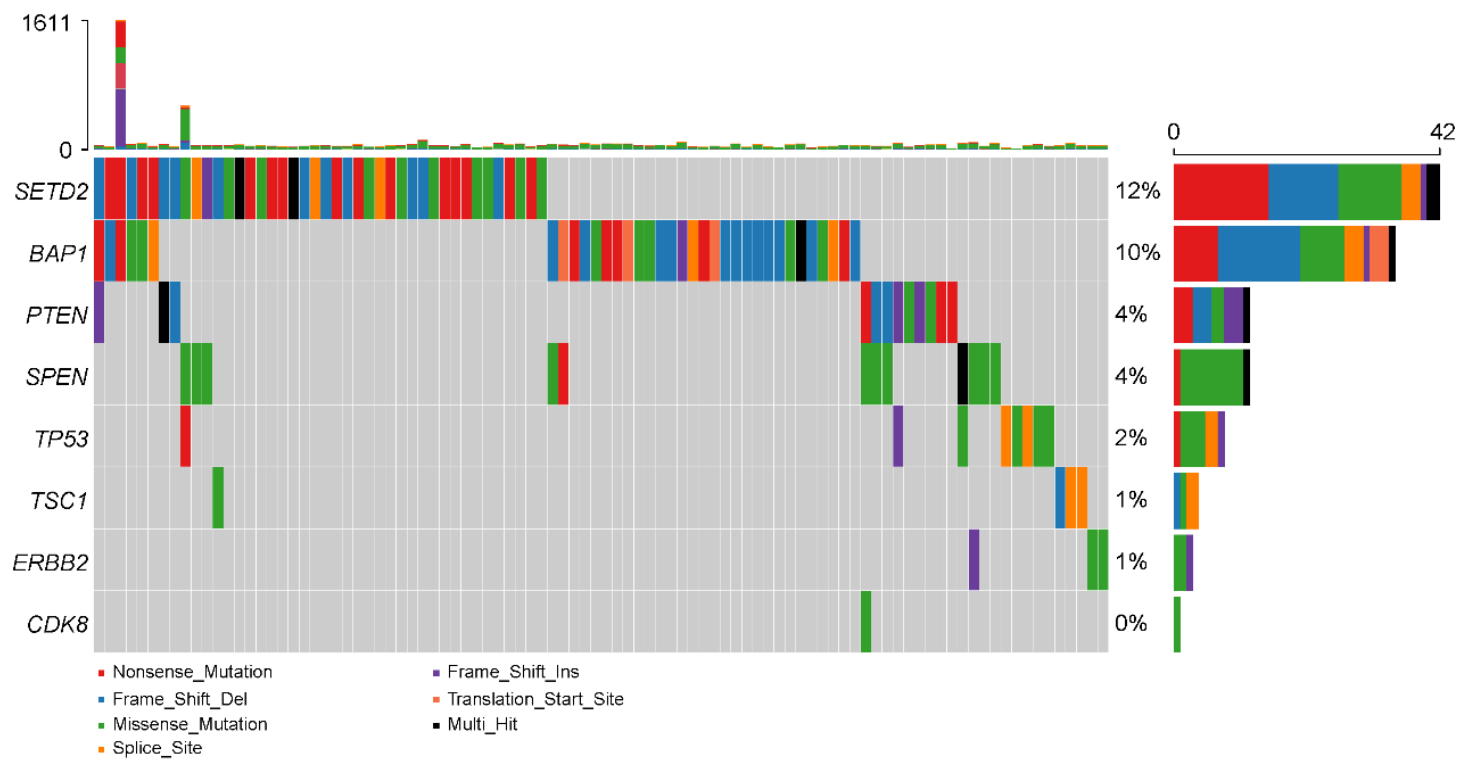

Figure S3 The mutation frequencies of the eight genes associated with poor prognosis in TCGA cohort. TCGA, The Cancer Genome Atlas.
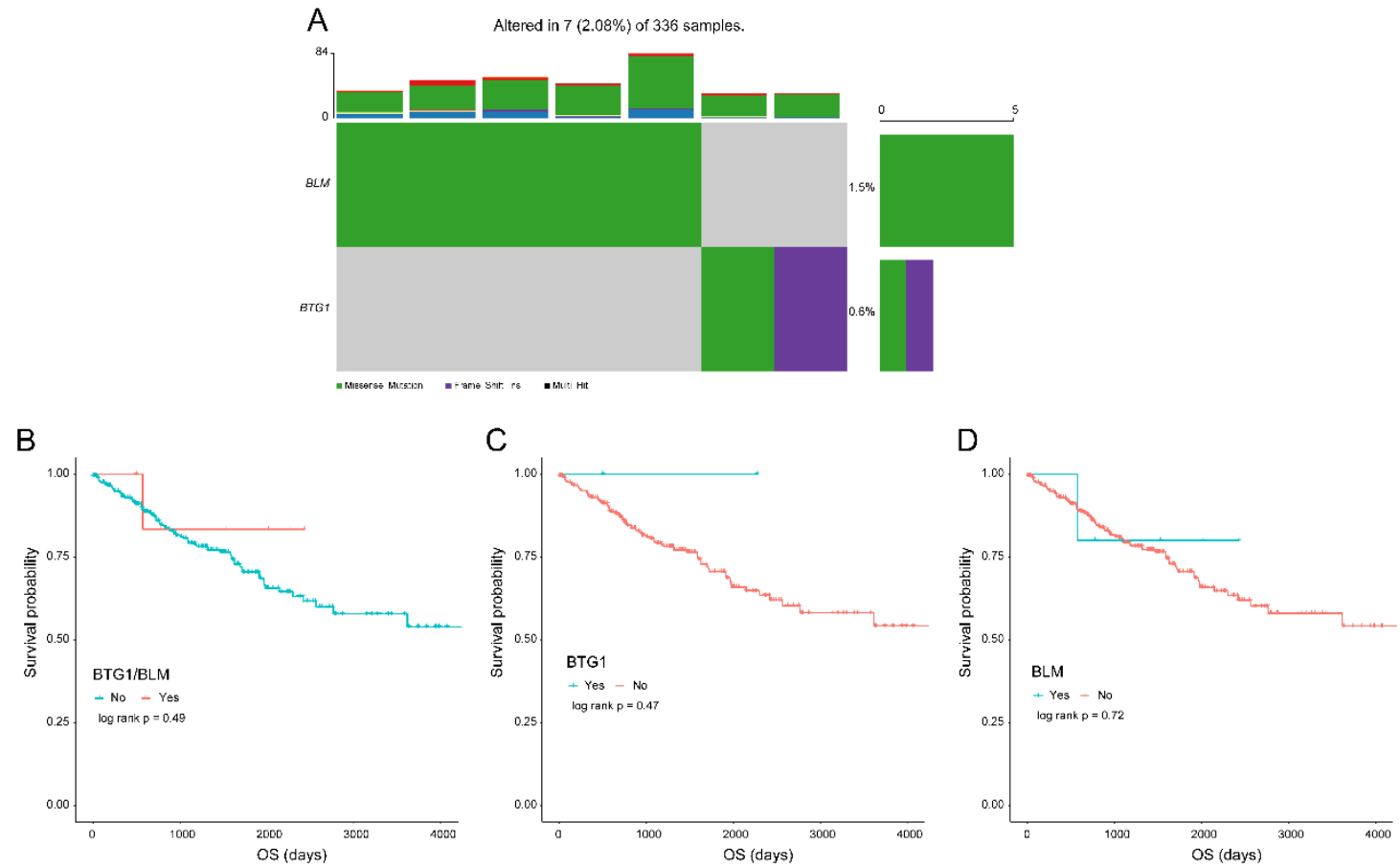

Figure S4 Validation of two genes (BTG1, $B L M)$ associated with good prognosis using TCGA cohort. (A) The mutation frequencies of BTG1 and BLM in TCGA cohort. (B) Kaplan-Meier curves for OS of ccRCC patients in TCGA cohort with mutated BTG1/BLM, (C) mutated BTG1, (D) mutated BLM. TCGA, The Cancer Genome Atlas; OS, overall survival; ccRCC, clear cell renal cell carcinoma 


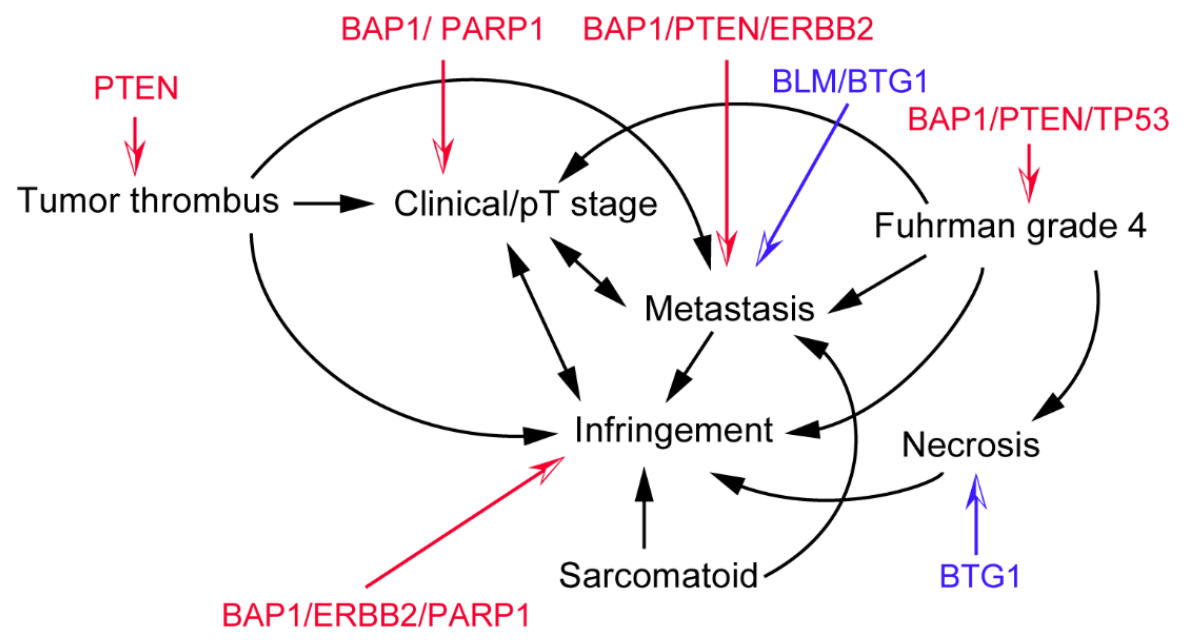

Figure S5 The interactions of different clinical indices. Genes associated with each clinical index were shown. Red, positively correlated; blue, negatively correlated.

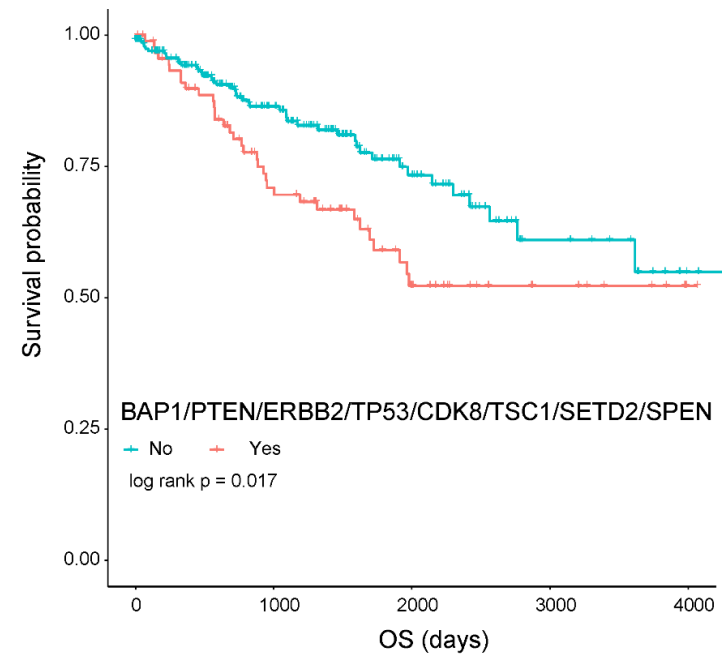

Figure S6 Kaplan-Meier curve for OS of ccRCC patients in TCGA cohort with 8 mutated genes associated with poor prognosis. TCGA, The Cancer Genome Atlas; OS, overall survival; ccRCC, clear cell renal cell carcinoma. 